\title{
Intelligent Controller for Synchronization New Three Dimensional Chaotic System
}

\author{
Alireza Sahab \\ Faculty of Engineering, Electrical Engineering Group, Islamic Azad University, Lahijan Branch, Iran \\ Email: sahab@liau.ac.ir \\ Masoud Taleb Ziabari \\ Faculty of Engineering, Computer Engineering Group, Ahrar University, Rasht, Iran \\ Email: m.t.ziabari@gmail.com
}

\begin{abstract}
One of the most important phenomena of some systems is chaos which is caused by nonlinear dynamics. In this paper, the new 3 dimensional chaotic system is first investigated and then utilized an intelligent controller based on brain emotional learning (BELBIC), this new chaotic system is synchronized. The BELBIC consists of reward signal which accepts positive values. Improper selection of the parameters causes an improper behavior which may cause serious problems such as instability of the system. It is needed to optimize these parameters. Genetic Algorithm (GA), Cuckoo Optimization Algorithm (COA), Particle Swarm Optimization Algorithm (PSO) and Imperialist Competitive Algorithm (ICA) are used to compute the optimal parameters for the reward signal of BELBIC. These algorithms can select appropriate and optimal values for the parameters. These minimize the Cost Function, so the optimal values for the parameters will be founded. Selected cost function is defined to minimizing the least square errors. Cost function enforces the system errors to decay to zero rapidly. Numerical simulation will show that this method much better, faster and more effective than previous methods can be new 3D chaotic system mode to bring synchronized.
\end{abstract}

Index Terms - New 3D chaotic system, Synchronization, BELBIC, Genetic Algorithm, Cuckoo Optimization Algorithm, Particle Swarm Optimization Algorithm, Imperialist Competitive Algorithm, Cost Function.

\section{INTRODUCTION}

In parallel with industrial and technological improvement, control systems and their control methods have become sophisticated. Control of new systems using previous old methods has become difficult. Further, considering human brain patterns and abilities in order to control and solve problems has resulted in emergence of new intelligent controlling methods which utilizes human brain operation patterns which are mentioned below. Brain Emotional Learning Based Intelligent Controller (BELBIC) was introduced for the first time by Lucas in 2004 [1]. Brain Emotional Learning Based Intelligent Controller (BELBIC) is an example of bioinspired control methods which is based on limbic system of mammalian brain. This controller is based on emotional behaviors in biological systems. Emotion is an emergent behavior in biological systems for fast decision making in complex environments. The advantages of this behavior cannot be neglected in creature survival [2]. During the past few years, the BELBIC has been used in control devices for several industrial applications. The BELBIC has been successfully employed for making decisions and controlling linear and nonlinear systems such as, Brain Emotional Learning Intelligent Controller (BELBIC) for the control of two benchmark nonlinear plants was applied in [3]. In [4], a problem of speed tracking of permanent magnet stepper motor has been discussed based on the static PID and newly type of intelligent control which mimics the emotional learning in limbic system of mammalians. Also BELBIC was used to control the Locally Linear Neuro-Fuzzy Model (LOLIMOT) of Washing Machine [5]. BELBIC was applied to a Switched Reluctance Motor (SRM) to tackle the speed and position control problem in [6]. Furthermore, BELBIC was applied for real time positioning of laboratorial overhead traveling crane in [7] In [8], BELBIC was applied to electrically heated microheat exchanger, which was a nonlinear plant. In [9], BELBIC is introduced to stabilize uncertain nonlinear systems via robust adaptive method. Also an intelligent adaptive approach for aerospace launch vehicle control is presented in [10]. Furthermore, the design of PID and BELBIC controllers in path tracking and controlling problem is studied in [11] and finally an intelligent autopilot control design for a 2-Dimensional helicopter model is studied in [12].

In this study, utilizing BELBIC model introduced in $[11,12]$, we will design an intelligent controller to synchronized two new 3D chaotic systems [13]. Simulation results depict that this proposed controller can synchronize these chaotic systems better than Active Control $[19,20]$. Finally, the parameters of BELBIC are improved by swarm intelligent algorithms.

The rest of the paper is organized as follows. The Brain Emotional Learning Based Intelligent Controller (BELBIC) is described in section 2. The new 3D chaotic system is described in section 3. Synchronization 
between two new 3D chaotic systems by BELBIC is proposed in section 4. Parameters of BELBIC are improved by Evolutionary Algorithms in section 5. The conclusion of this study is provided in section 6 .

\section{BRAIN LEARNING BASED INTELLIGENT CONTROLLER (BELBIC)}

In this method, emotional factors like excitement and anxiety are the roots of learning. Here, the roots of anxiety are assumed as some stimulants and the control system should react in the way that reduces the anxiety of the system caused by these stimulants. The Brain Emotional Learning (BEL) is divided into two parts, very roughly corresponding to the amygdala and the orbitofrontal cortex, respectively. The amygdaloid part receives inputs from the thalamus and from cortical areas, while the orbital part receives inputs from the cortical areas and the amygdala only. The system also receives reinforcing (REW) signal. The emotional learning model in amygdala and orbitofrontal corex is illustrated in Fig 1.

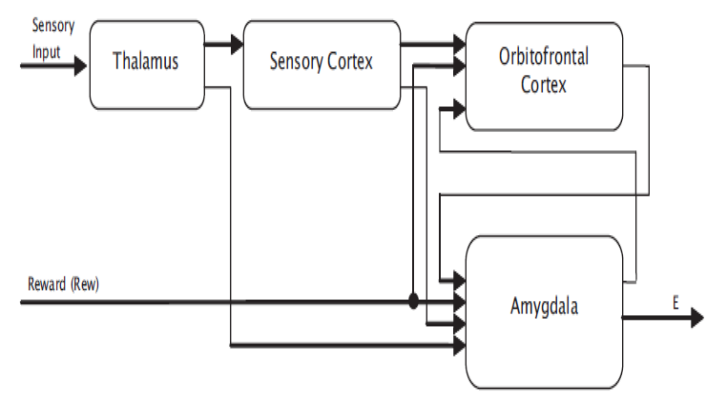

Fig. 1. Scheme of BELBIC structure [1]

BELBIC has some input sensors that can be chosen by designer. Each input sensor has two different states that can be described as.

$$
\begin{gathered}
A_{i}=s_{i} v_{i} \\
O_{i}=s_{i} w_{i}
\end{gathered}
$$

In which $\mathrm{s}$, is the input sensor and $\mathrm{v}, \mathrm{w}$ are two states that are depended on input sensor. Index $\mathrm{i}$ represents the iTh sensor and its related states. These two equations will be updated by following equations $[11,12]$.

$$
\begin{aligned}
\Delta v_{i} & =\alpha s_{i} \max \left(0, \text { rew }-\sum A_{i}\right) \\
\Delta w_{i} & =\beta s_{i}\left(\operatorname{rew}-\sum A_{i}-\sum O_{i}-\max \left(s_{i}\right)\right)
\end{aligned}
$$

In which $\alpha, \beta$ are training coefficients and rew is the reward signal. Amygdala acts as an actuator and orbitofrontal corex acts as a preventer. Therefore the control signal of BELBIC is:

$$
u=\sum A_{i}-\sum O_{i}
$$

This paper uses the continuous form of BELBIC. In continuous form the BELBIC states are updated by following equations.

$$
\begin{aligned}
& \dot{v}_{l}=\alpha s_{i}\left(\text { rew }-A_{i}\right) \\
& \dot{w}_{l}=\beta s_{i}\left(\text { rew }+s_{i}+O_{i}-A_{i}\right)
\end{aligned}
$$

A BELBIC controller has to be designed to synchronize two chaotic systems. For traction force sensory inputs are considered.

$$
s_{i}=e_{i}
$$

$e_{i}$ is the error between the master system and the slave system. The structure of the control system is illustrated in Fig 2.

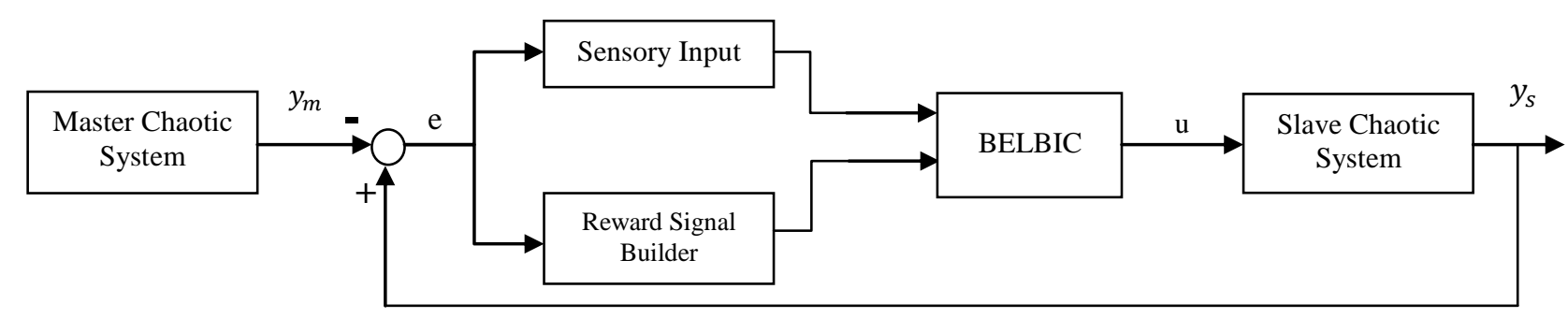

Fig. 2. Control system configuration using BELBIC

The reward signal will be obtained the reward function. This function has a great role in BELBIC. The designer must define a reward function that has its maximum values in the most desired regions. In this study, the reward function is chosen as a linear function of system error.

$$
\operatorname{Rew}_{i}=k_{1 i} e_{i}+k_{2 i}
$$

$k_{1 i}$ and $k_{2 i}$ are the positive parameters of the reward function. The reward function for this BELBIC controller is as Fig 3. 


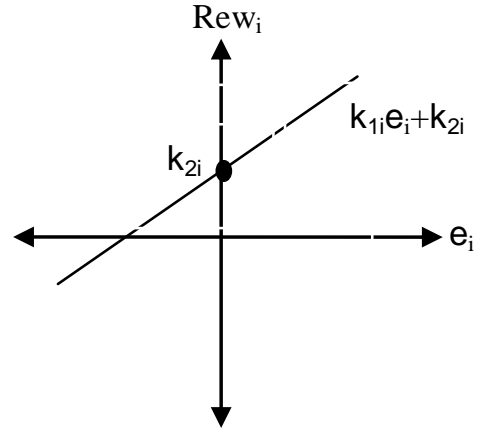

Fig. 3. Reward Function

\section{SYSTEM DESCRIPTION}

Recently, Dadras and Momeni proposed the threedimensional autonomous chaotic system that generating two, three and four-scroll attractors [13]. The system is described by:

$$
\begin{aligned}
& \dot{x}=y-a x+b y z \\
& \dot{y}=c y-x z+z \\
& \dot{z}=d x y-h z
\end{aligned}
$$

Here $\mathrm{x}, \mathrm{y}, \mathrm{z}$ are the state variables and $\mathrm{a}, \mathrm{b}, \mathrm{c}, \mathrm{d}, \mathrm{h}$ are the positive constant parameters. When $\mathrm{a}=3, \mathrm{~b}=2.7, \mathrm{c}=$ $4.7, \mathrm{~d}=2, \mathrm{~h}=9$, the system (7) is chaotic witn the Lyapunov exponents $\mathrm{L}_{1}=0.631, \mathrm{~L}_{2}=0, \mathrm{~L}_{3}=-7.931$. The corresponding phase portraits are depicted in Fig 4 and the state trajectory of the system (7) is displayed in Fig 5.

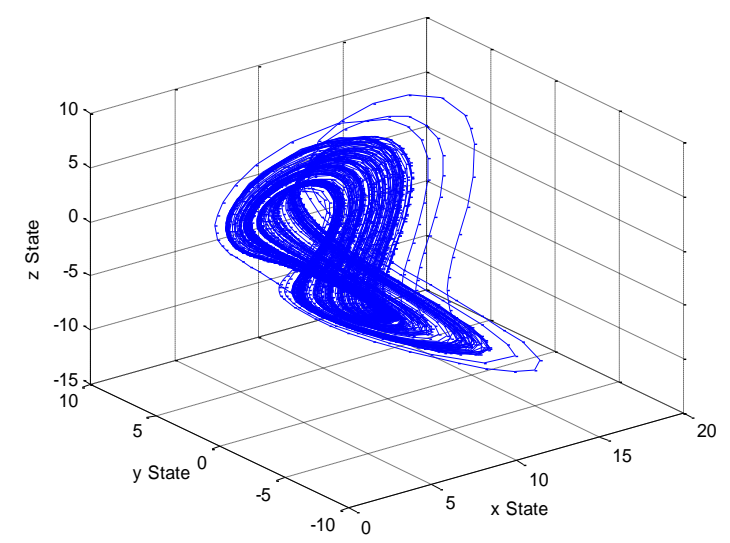

Fig. 4. Phase portraits of the 3D chaotic attractors (7) in (a) the xy space, (b) the xz space, (c) the yz space, (d) the xyz space.

\section{SyNCHRONIZATION BETWEEN TWO NEW 3D CHAOTIC SYSTEM}

In this section, the BELBIC is applied to synchronize between two new 3D chaotic systems. Suppose the driving system takes the following froms:

$$
\begin{aligned}
& \dot{x}_{1}=y_{1}-a x_{1}+b y_{1} z_{1} \\
& \dot{y}_{1}=c y_{1}-x_{1} z_{1}+z_{1} \\
& \dot{z}_{1}=d x_{1} y_{1}-h z_{1}
\end{aligned}
$$

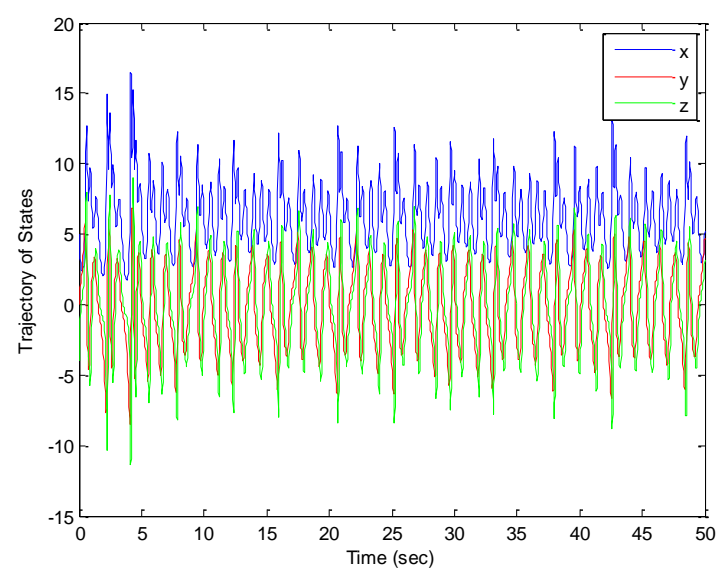

Fig. 5. State trajectory of the 3D chaotic attractors (7).

And the response system is presented as follows

$$
\begin{aligned}
& \dot{x}_{2}=y_{2}-a x_{2}+b y_{2} z_{2}+u_{1}(t) \\
& \dot{y}_{2}=c y_{2}-x_{2} z_{2}+z_{2}+u_{2}(t) \\
& \dot{z}_{2}=d x_{2} y_{2}-h z_{2}+u_{3}(t)
\end{aligned}
$$

Where $u_{1}(t), u_{2}(t)$ and $u_{3}(t)$ are control functions to be determined to achieve the synchronization between two systems (8) and (9). Define state errors between system (8) and (9) as follows

$$
\begin{aligned}
& e_{x}=x_{2}-x_{1} \\
& e_{y}=y_{2}-y_{1} \\
& e_{z}=z_{2}-z_{1}
\end{aligned}
$$

We obtain the following error dynamical system by subtracting the driving system (8) from the response system (9).

$$
\begin{gathered}
\dot{e}_{x}=e_{y}-a e_{x}+b\left(y_{2} z_{2}-y_{1} z_{1}\right)+u_{1}(t) \\
\dot{e}_{y}=c e_{y}+e_{z}-\left(x_{2} z_{2}-x_{1} z_{1}\right)+u_{2}(t) \\
\dot{e}_{z}=d\left(x_{2} y_{2}-x_{1} y_{1}\right)-h e_{z}+u_{3}(t)
\end{gathered}
$$

Thus, the error system (11) to be controlled with control inputs $\mathrm{u}_{1}(\mathrm{t}), \mathrm{u}_{2}(\mathrm{t})$ and $\mathrm{u}_{3}(\mathrm{t})$ as functions of error states $e_{x}, e_{y}$ and $e_{z}$. When system (11) is stabilized by control inputs $\mathrm{u}_{1}(\mathrm{t}), \mathrm{u}_{2}(\mathrm{t})$ and $\mathrm{u}_{3}(\mathrm{t}), \mathrm{e}_{\mathrm{x}}, \mathrm{e}_{\mathrm{y}}$ and $\mathrm{e}_{\mathrm{z}}$ will converage to zeroes as time $t$ tends to infinity. Which implies that system (8) and (9) are synchronized.

To achieve this purpose, Input sensory of BELBIC is chosen as (12).

$$
\left\{\begin{array}{l}
s_{1}=e_{x} \\
s_{2}=e_{y} \\
s_{3}=e_{z}
\end{array}\right.
$$

The reward function's parameters for the BELBIC controller are as follows. 


$$
\left\{\begin{array}{l}
\operatorname{rew}_{1}=k_{1} e_{x}+k_{2} \\
\text { rew }_{2}=k_{3} e_{y}+k_{4} \\
\text { rew }_{3}=k_{5} e_{z}+k_{6}
\end{array}\right.
$$

The parameters $\alpha$ and $\beta$ are equal to 1 and 3 respectively. We take the reward gains as $k_{i}=1$ for $i=1,2,3,4,5,6$. For drive and response systems, we take initial conditions $\left(x_{1}(0), y_{1}(0), z_{1}(0)\right)=(-5,26,14)$ and $\left(x_{2}(0), y_{2}(0), z_{2}(0)\right)=(24,2,-6)$. After using BELBIC, we compare the results with the results obtained by Active Control [19]. Synchronization errors $\left(e_{x}, e_{y}, e_{z}\right)$ of BELBIC and Active Control [19] in new $3 \mathrm{D}$ chaotic systems are shown in fig 6 and fig 7 . The time response of the control inputs $\left(u_{1}, u_{2}, u_{3}\right)$ of BELBIC and Active Control [19] to the synchronize new 3D chaotic systems are shown in fig 8 and fig 9. The time response of $(x, y, z)$ states for drive system (8) and response system (9) via BELBIC is shown in fig 10.

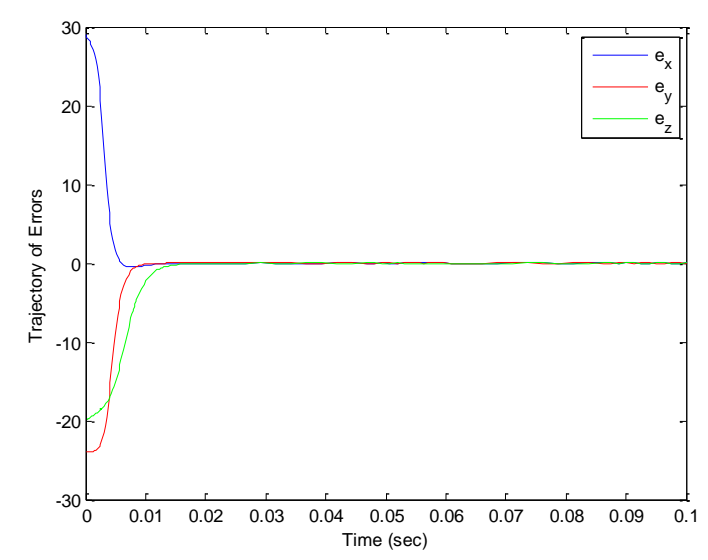

Fig. 6. Synchronization errors $\left(e_{x}, e_{y}, e_{z}\right)$ in drive system (8) and response system (9) via BELBIC.

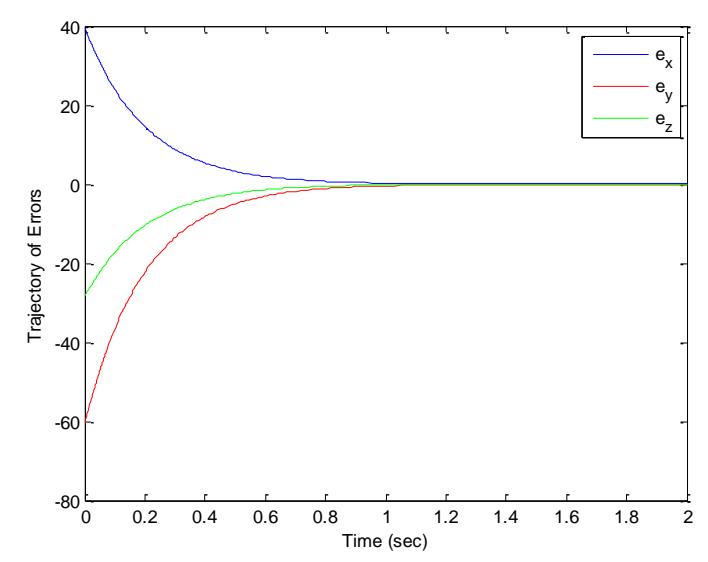

Fig. 7. Synchronization errors $\left(e_{x}, e_{y}, e_{z}\right)$ in drive system (8) and response system (9) via Active Control [19].

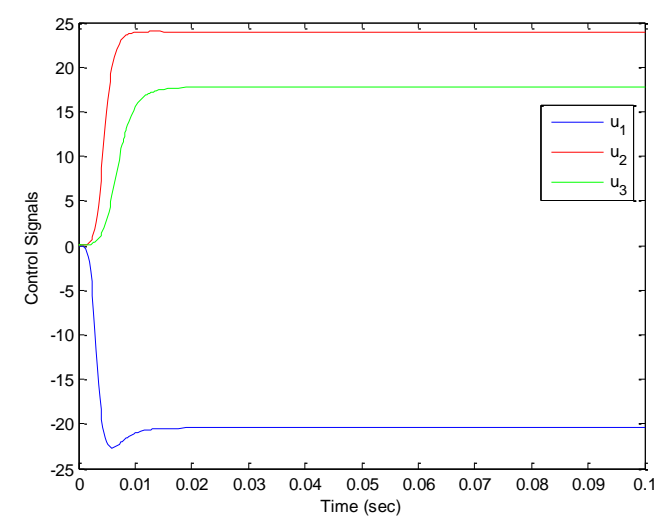

Fig. 8. The time response of the control inputs $\left(\mathrm{u}_{1}, \mathrm{u}_{2}, \mathrm{u}_{3}\right)$ via BELBIC.

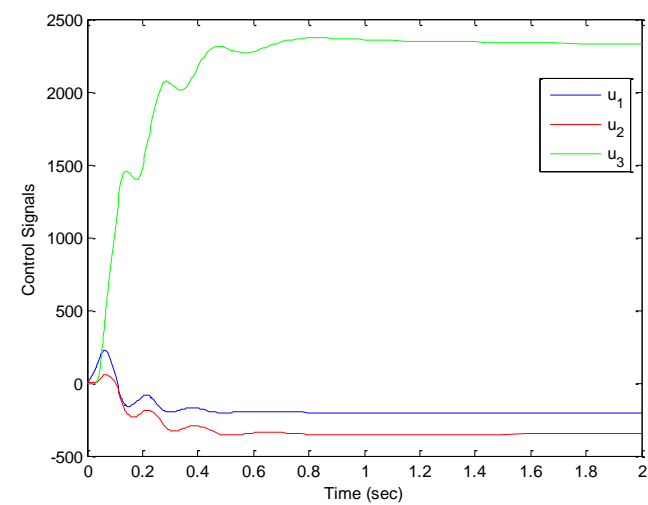

Fig. 9. The time response of the control inputs $\left(\mathrm{u}_{1}, \mathrm{u}_{2}, \mathrm{u}_{3}\right)$ via Active Control [19].
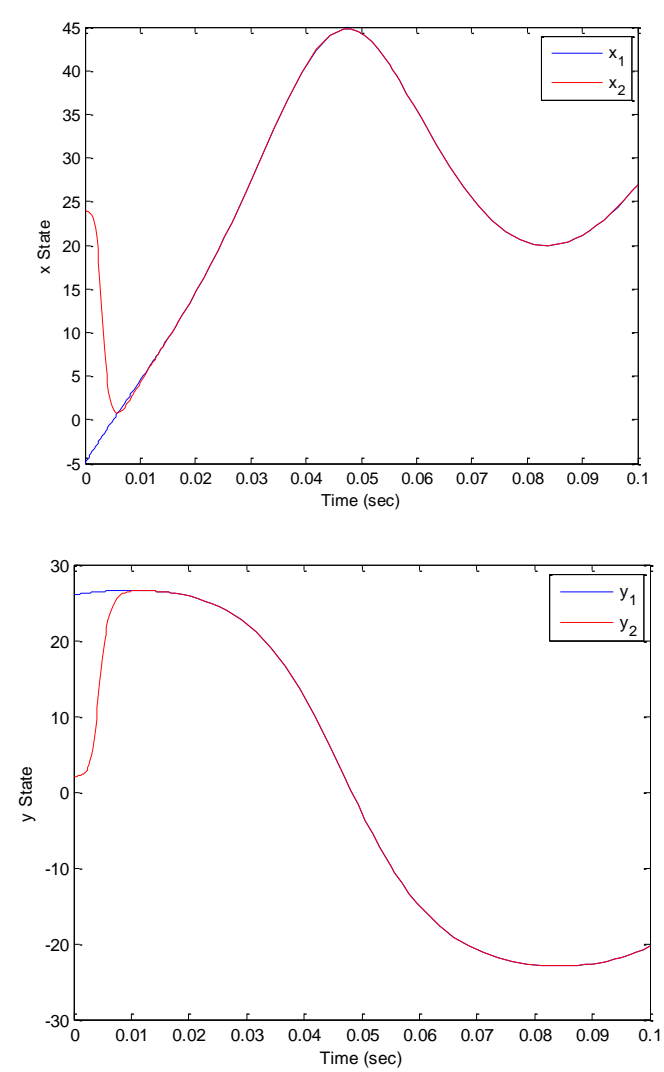


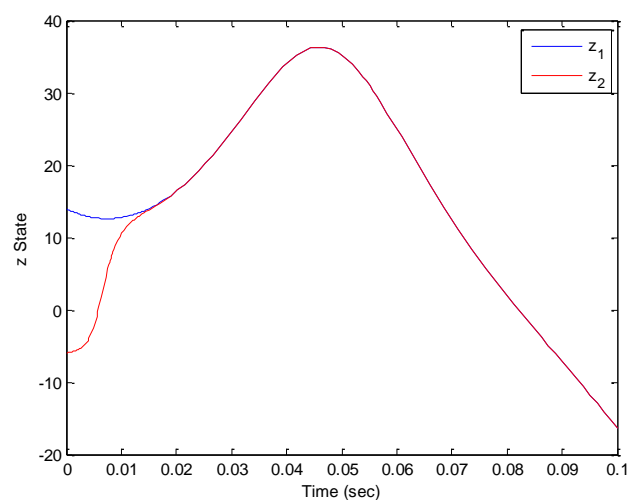

Fig. 10. The time response of signals $(x, y, z)$ for drive system $(8)$ and response system (9) via BELBIC.

\section{IMPROVING THE PARAMETERS OF CONTROLLER}

The reward signal is very important for BELBIC. The system responses differently to each value. It is necessary to select proper parameters to obtain a good response because the improper selection of parameters leads to inappropriate responses or even may lead to instability of the system. The Genetic Algorithm [14,15], Cuckoo Optimization Algorithm [16], Particle Swarm Optimization Algorithm [17] and Imperialist Competitive Algorithm [18] are used to search the optimal parameter $(k)$ in order to guarantee the stability of the systems by ensuring negativity of the Lyapunov function and having a suitable time response. The reward signals in the equation (13) are optimized by the Cost Function in the equation 14. The selected cost function is defined to minimize the least square errors. The cost function enforces the synchronization errors to decay to zero rapidly.

$$
f\left(e_{1}, e_{2}, \cdots, e_{n}\right)=\frac{1}{n} \sqrt{\sum_{i=1}^{n} e_{i}^{2}}
$$

Table 1. Genetic Algorithm Parameters.

\begin{tabular}{|c|c|}
\hline Parameters & Values \\
\hline Size population & 80 \\
\hline Maximum of generation & 30 \\
\hline Prob.crossover & 0.75 \\
\hline Prob.mutation & 0.001 \\
\hline$k$ Search interval & {$[110]$} \\
\hline
\end{tabular}

Table 2. Cuckoo Optimization Algorithm Parameters.

\begin{tabular}{|c|c|}
\hline Parameters & Values \\
\hline Size clusters & 2 \\
\hline $\begin{array}{c}\text { Maximum number of } \\
\text { cuckoo }\end{array}$ & 80 \\
\hline Size initial population & 5 \\
\hline $\begin{array}{c}\text { Maximum iterations of } \\
\text { cuckoo }\end{array}$ & 30 \\
\hline$k$ Search interval & {$[110]$} \\
\hline
\end{tabular}

Table 3. Particle Swarm Optimization Algorithm Parameters.

\begin{tabular}{|c|c|}
\hline Parameters & Values \\
\hline Size population & 80 \\
\hline Maximum iterations & 30 \\
\hline $\begin{array}{c}\text { Initial and Final value of the global best } \\
\text { acceleration factor }\end{array}$ & 2 and 2 \\
\hline Initial and Final value of the inertia factor & $\begin{array}{c}1 \text { and } \\
0.99\end{array}$ \\
\hline$k$ Search interval & {$[110]$} \\
\hline
\end{tabular}

Table 4. Imperialist Competitive Algorithm Parameters.

\begin{tabular}{|c|c|}
\hline Parameters & Values \\
\hline Number of Initial Countries & 80 \\
\hline Number of Decades & 30 \\
\hline Number of Initial Imperialists & 8 \\
\hline Revolution Rate & 0.3 \\
\hline$k$ Search interval & {$[110]$} \\
\hline
\end{tabular}

The optimal parameters of reward signals using genetic algorithm, cuckoo optimization algorithm, particle swarm optimization algorithm and imperialist competitive algorithm are listed in table. 5 .

Table 5. Optimal Parameters of Reward Signals.

\begin{tabular}{|c|c|c|c|c|c|c|c|c|}
\cline { 2 - 9 } \multicolumn{1}{c|}{} & $k_{1}$ & $k_{2}$ & $k_{3}$ & $k_{4}$ & $k_{5}$ & $k_{6}$ & $\alpha$ & $\beta$ \\
\hline GA & 3.55 & 1.26 & 6.01 & 8.02 & 3.46 & 9.49 & 9.46 & 1.09 \\
\hline PSO & 3.79 & 6.27 & 5.64 & 3.97 & 2.92 & 8.11 & 7.19 & 1.53 \\
\hline COA & 10 & 7.54 & 10 & 8.58 & 1.66 & 10 & 8.51 & 1.28 \\
\hline ICA & 4.03 & 1 & 5.89 & 10 & 1 & 10 & 10 & 1 \\
\hline
\end{tabular}

Synchronization errors $\left(e_{x}, e_{y}, e_{z}\right)$ in new $3 D$ chaotic systems are shown in order Fig 11 to Fig 13.

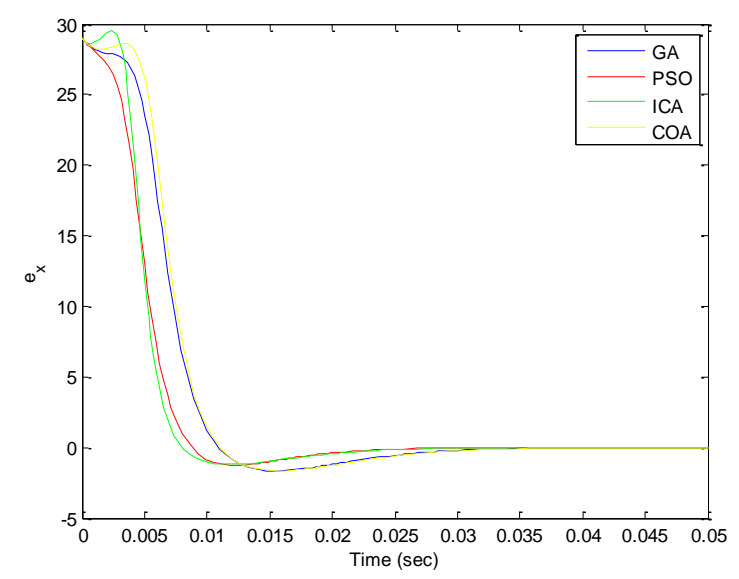

Fig. 11. Synchronization error $\left(e_{\mathrm{x}}\right)$ in drive system (8) and response system (9). 


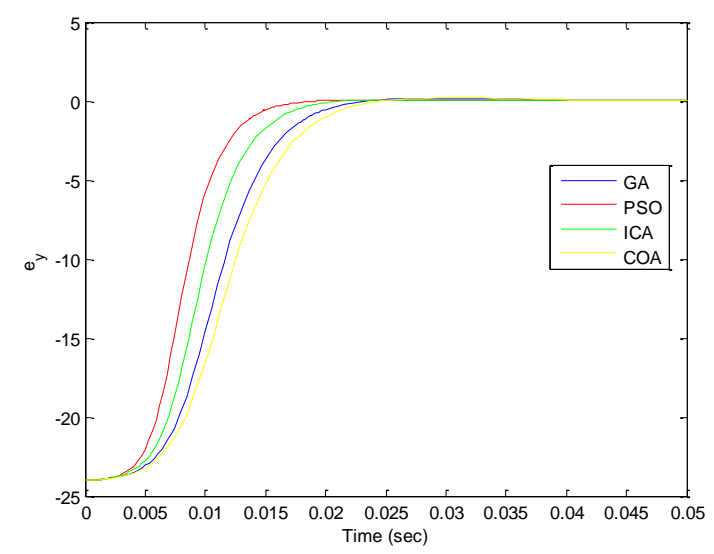

Fig. 12. Synchronization error $\left(\mathrm{e}_{\mathrm{y}}\right)$ in drive system (8) and response system (9).

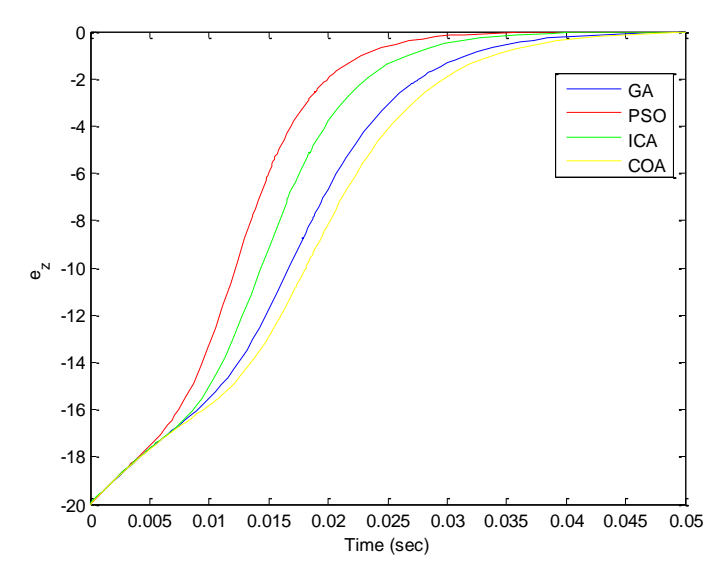

Fig. 13. Synchronization error $\left(e_{z}\right)$ in drive system (8) and response system (9).

\section{CONCLUSION}

In this work, Chaos synchronization have been discussed. Many methods synchronized chaotic systems but many above-mentioned methods can only applied some given chaotic systems, some methods will produce the singularity problem in synchronizing the chaotic system and most of the methods in the literatures need more than one variable information of the master system. In order to achieve a proper synchronization between two new 3D chaotic systems, an intelligent controller based on brain emotional learning (BELBIC) was utilized. The BELBIC consists of reward signal which accepts positive values. Improper selection of the parameters causes an improper behavior which may cause serious problems such as instability of the system. Evolutionary Algorithms were well known optimization methods. Genetic Algorithm, Cuckoo Optimization Algorithm, Particle Swarm Optimization Algorithm and Imperialist Competitive Algorithm optimized the BELBIC. For this reason these algorithms minimized the cost function to find minimum current value for it. On the other hand cost function found minimum value to minimize the least square errors. Finally, it has been proved that the controller is faster, more optimal and more efficient than active control.

\section{REFERENCES}

[1] Lucas C, Shahmirzadi D, and Sheikholeslami N, "Introducing BELBIC: Brain emotional learning based intelligent control", Int. J. Intell. Automat. Soft Comput. 2004; 10(1): 11-22.

[2] Tole Sutikno, Mochammad Facta, G.R. Arab Markadeh, "Editorial Progress in Artificial Intelligence Techniques: from Brain to Emotion", TELKOMNIKA, Vol.9, No.2, August 2011, pp. 201-202.

[3] ALI REZA MEHRABIAN, CARO LUCAS, "INTELLIGENT ADAPTIVE CONTROL OF NONLINEAR SYSTEMS BASED ON EMOTIONAL LEARNING APPROACH", International Journal on Artificial Intelligence Tools,Vol. 16, No. 1 (2007) 69-84.

[4] Amir Mehdi Yazdani, Somaiyeh Mahmoudzadeh, "Emotional Learning as a Cognitive Approach for High Performance Control of Permanent Magnet Stepper Motor", Int. J. Comp. Tech. Appl., Vol 2 (4), 1008-1015.

[5] Rasoul Mohammadi Milasi, Mohammad Reza Jamali, and Caro Lucas, "Intelligent Washing Machine: A Bioinspired and Multi-objective Approach", International Journal of Control, Automation, and Systems, vol. 5, no. 4, pp. 436443, August 2007.

[6] Hossein Rouhani, Arash Sadeghzadeh, Caro Lucas and Babak Nadjar Araabi, "Emotional learning based intelligent speed and position control applied to neurofuzzy model of switched reluctance motor", Control and Cybernetics vol. 36 (2007) No. 1.

[7] Mohammad Reza Jamali, Arash Arami, Babak Hosseini, Behzad Moshiri and Caro Lucas, "REAL TIME EMOTIONAL CONTROL FOR ANTI-SWING AND POSITIONING CONTROL OF SIMO OVERHEAD TRAVELING CRANE", International Journal of Innovative Computing, Information and Control, Volume 4, Number 9, September 2008 pp. 2333-2344.

[8] Hossein Rouhani, Mahdi Jalili, Babak N. Araabi, Wolfgang Eppler, Caro Lucas, "Brain emotional learning based intelligent controller applied to neurofuzzy model of micro-heat exchanger", Expert Systems with Applications 32 (2007) 911-918.

[9] Ali Reza Mehrabian, and Caro Lucas, "Emotional Learning based Intelligent Robust Adaptive Controller for Stable Uncertain Nonlinear Systems", INTERNATIONAL JOURNAL OF COMPUTATIONAL INTELLIGENCE VOLUME 2 NUMBER 42005 ISSN 1304-4508.

[10] Ali Reza Mehrabian, Caro Lucas, Jafar Roshanian, "Aerospace launch vehicle control: an intelligent adaptive approach", Aerospace Science and Technology 10 (2006) 149-155.

[11] Saeed Jafarzadeh, Rooholah Mirheidari, Mohammad Reza Jahed Motlagh, Mojtaba Barkhordari, "Designing PID and BELBIC Controllers in Path Tracking Problem”, Int. J. of Computers, Communications \& Control, ISSN 1841-9836, E-ISSN 1841-9844,Vol. III (2008), Suppl. issue: Proceedings of ICCCC 2008, pp. 343-348.

[12] Saeed Jafarzadeh, Rooholah Mirheidari, Mohammad Reza Jahed Motlagh, Mojtaba Barkhordari, "Intelligent Autopilot Control Design for a 2-DOF Helicopter Model", Int. J. of Computers, Communications \& Control, ISSN 1841-9836, E-ISSN 1841-9844, Vol. III (2008), Suppl. issue: Proceedings of ICCCC 2008, pp. 337-342.

[13] Sara Dadras, Hamid Reza Momeni, "A novel threedimensional autonomous chaotic system generating two, 
three and four-scroll attractors", Physics Letters A 373 (2009) 3637-3642.

[14] Ahmed BELHANI, Khaled BELARBI and Fateh MEHAZEM. DESIGN OF MULTIVARIABLE BACKSTEPPING CONTROLLER USING GENETIC ALGORITHM. ACSE 05 Conference, 19-21 December 2005, CICC, Cairo, Egypt.

[15] Michalewicz, Z. Genetic Algorithm + Data Structures = Evolution Programs, $2^{\text {nd }}$ Edition, Springler Verlag 1994.

[16] Ramin Rajabioun, Cuckoo Optimization Algorithm, Applied Soft Computing 11 (2011) 5508-5518.

[17] V. Rashtchi, H. Shayeghi, M. Mahdavi, A. Kimiyaghalam, E. Rahimpour, Using an Improved PSO Algorithm for Parameter Identification of Transformer Detailed Model, International Journal of Electrical Power and Energy Systems Engineering 1;3 @ c www.waset.org Summer 2008.

[18] Esmaeil Atashpaz Gargari \& Caro Lucas, Imperialist Competitive Algorithm: An Algorithm for Optimization Inspired by Imperialistic Competition, 2007 IEEE Congress on Evolutionary Computation (CEC 2007). pp 4661 - 4667.

[19] Sarasu Pakiriswamy and Sundarapandian Vaidyanathan, ACTIVE CONTROLLER DESIGN FOR THE GENERALIZED PROJECTIVE SYNCHRONIZATION OF THREE-SCROLL CHAOTIC SYSTEMS, International Journal of Advanced Information Technology (IJAIT) Vol. 2, No.1, February 2012.

[20] Sarasu Pakiriswamy, Sundarapandian Vaidyanathan, Generalized Projective Synchronization of Three-Scroll
Chaotic Systems via Active Control, Advances in Computer Science and Information Technology. Computer Science and Engineering, Volume 85, 2012, pp 146-155.

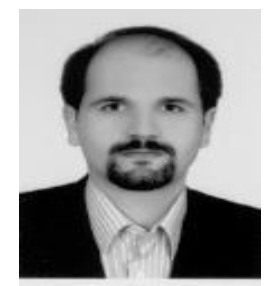

Ali Reza Sahab. Received the B.S. in control engineering from KNT the University of Technology, Tehran, Iran in 2001 and the M.S. and $\mathrm{Ph} . \mathrm{D}$. degrees in control engineering from Shahrood University of Technology, Shahrood, Iran in 2003 and 2009 respectively.

$\mathrm{He}$ is a staff member of Electrical Group, Engineering Faculty of Islamic Azad University, Lahijan Branch. His research interests include nonlinear control and intelligent systems.

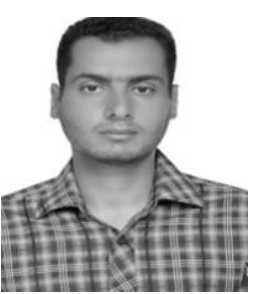

Masoud Taleb Ziabari. Received the B.S. in computer hardware from Islamic Azad University, Yazd, Iran in 2005. He Received the M.S. student in major of Mechatronic in Islamic Azad University Qazvin Branch, Qazvin, Iran. His research interests include nonlinear control and intelligent systems.

How to cite this paper: Alireza Sahab, Masoud Taleb Ziabari,"Intelligent Controller for Synchronization New Three Dimensional Chaotic System", IJMECS, vol.6, no.7, pp.40-46, 2014.DOI: 10.5815/ijmecs.2014.07.06 